\title{
Correction to: High Content Solid Dispersions for Dose Window Extension: A Basis for Design Flexibility in Fused Deposition Modelling
}

\author{
Rydvikha Govender ${ }^{1,2}$ (D) - Susanna Abrahmsén-Alami ${ }^{\prime} \cdot$ Staffan Folestad ${ }^{\prime} \cdot$ Anette Larsson ${ }^{2}$
}

(C) Springer Science+Business Media, LLC, part of Springer Nature 2021

\section{Correction to: Pharm Res (2020) 37: 9 \\ https://doi.org/I0.1007/s I 1095-019-2720-6}

This article was updated to replace funding information that was mistakenly deleted by the publisher and to remove extraneous symbols that were inserted by the publisher postpublication.

The online version of the original article can be found at https://doi.org/l 0 . |007/s | |095-019-2720-6

Rydvikha Govender

rydvikha.govender@astrazeneca.com

Pharmaceutical Technology and Development, AstraZeneca,

Pepparedsleden I, 43। 83 Gothenburg, Mölndal, Sweden

2 Chemistry and Chemical Engineering, Chalmers University of

Technology, Gothenburg, Sweden 